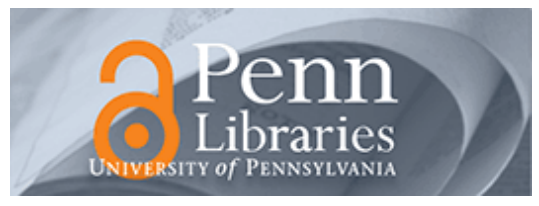

University of Pennsylvania

ScholarlyCommons

Finance Papers

Wharton Faculty Research

$11-2016$

\title{
Mad and Misleading: Incidental Anger Promotes Deception
}

Jeremy A. Yip

University of Pennsylvania

Maurice E. Schweitzer

University of Pennsylvania

Follow this and additional works at: https://repository.upenn.edu/fnce_papers

Part of the Finance and Financial Management Commons

\section{Recommended Citation}

Yip, J. A., \& Schweitzer, M. E. (2016). Mad and Misleading: Incidental Anger Promotes Deception. Organizational Behavior and Human Decision Processes, 137207-217. http://dx.doi.org/10.1016/ j.obhdp.2016.09.006

This paper is posted at ScholarlyCommons. https://repository.upenn.edu/fnce_papers/92

For more information, please contact repository@pobox.upenn.edu. 


\title{
Mad and Misleading: Incidental Anger Promotes Deception
}

\begin{abstract}
Emotions influence ethical behavior. Across four studies, we demonstrate that incidental anger, anger triggered by an unrelated situation, promotes the use of deception. In Study 1, participants who felt incidental anger were more likely to deceive their counterpart than those who felt neutral emotion. In Study 2, we demonstrate that empathy mediates the relationship between anger and deception. In Study 3 , we contrast anger with another negative-valence emotion, sadness. We find that participants who felt incidental anger were more likely to use deception than were participants who felt incidental sadness or neutral emotion. In Study 4, we show that incentives moderate the relationship between anger and deception. Collectively, our work reveals that incidental anger promotes unethical behavior because angry people become less empathetic when pursuing their self-interest.
\end{abstract}

\section{Keywords}

lying, emotion, anger, empathy, negotiation, conflict, self-interest, ethics

Disciplines

Finance and Financial Management 


\title{
Mad and Misleading: Incidental Anger Promotes Deception
}

\author{
Jeremy A. Yip \\ The Wharton School \\ University of Pennsylvania \\ 3730 Walnut Street, 517 JMHH \\ Philadelphia, PA 19104 \\ Email: yip@wharton.upenn.edu \\ Maurice E. Schweitzer \\ The Wharton School \\ University of Pennsylvania \\ 3730 Walnut Street, 544 JMHH \\ Philadelphia, PA 19104 \\ Email: schweitzer@wharton.upenn.edu
}

\section{Organizational Behavior and Human Decision Processes}

\author{
Forthcoming
}

Cite:

Yip, J. A., \& Schweitzer, M. E. (2016). Mad and misleading: Incidental anger promotes deception. Organizational Behavior and Human Decision Processes. 


\section{Acknowledgements}

We thank Madan Pillutla and two anonymous reviewers for their helpful suggestions and guidance. We are grateful for the financial support and research assistance of the Wharton Behavioral Lab. We appreciate the helpful feedback and advice from Kelly Kiyeon Lee, Emma Levine, and members of the OID Schweitzer Lab. 


\section{Highlights}

- We demonstrate that incidental anger, anger triggered by an unrelated situation, promotes unethical behavior.

- People who feel incidental anger are more likely to deceive their counterparts than people who feel neutral emotion.

- Empathy mediates the relationship between incidental anger and deception.

- Incidental anger increases deception relative to sadness.

- Incentives moderate the relationship between incidental anger and deception. 


\begin{abstract}
Emotions influence ethical behavior. Across four studies, we demonstrate that incidental anger, anger triggered by an unrelated situation, promotes the use of deception. In Study 1, participants who felt incidental anger were more likely to deceive their counterpart than those who felt neutral emotion. In Study 2, we demonstrate that empathy mediates the relationship between anger and deception. In Study 3, we contrasted anger with sadness. We find that participants who felt incidental anger were more likely to use deception than were participants who felt another negative-valence emotion. In Study 4, we show that incentives moderate the relationship between anger and deception. Collectively, our work reveals that incidental anger promotes unethical behavior because angry people become less empathetic when pursuing their selfinterest.
\end{abstract}

Keywords: Lying; Emotion; Anger; Empathy; Negotiation; Conflict; Self-Interest; Advice 


\section{Mad and Misleading: Incidental Anger Promotes Deception}

Deception pervades organizational life and represents a significant challenge in domains ranging from negotiations to job interviews to expense reporting. In one study, the Coalition Against Insurance Fraud (2012) found that individuals file nearly $\$ 80$ billion in fraudulent insurance claims in the United States. Financial incentives explain some deceptive behavior (Tenbrunsel, 1998), but recent research suggests that deception is also influenced by a number of psychological factors including perceptions of inequity (Gino \& Pierce, 2010), ego-depletion (Gino, Schweitzer, Mead, \& Ariely, 2011), power (Pitesa \& Thau, 2013), and trust (Yip \& Schweitzer, 2015).

One psychological factor that may be particularly relevant to the deception decision process is emotion (Gino \& Shea, 2012; Gaspar \& Schweitzer, 2013; Moran \& Schweitzer, 2008; Zhong, 2011). In this work, we consider the potential influence of anger on deception. Prior work has linked anger with a number of thoughts and behaviors that are related to deception (Barry \& Oliver, 1996; Olekalns \& Smith, 2009). For example, anger curtails cooperation (Lount, Zhong, Sivanathan, \& Murnighan, 2008), and increases the rejection of ultimatum game offers (Pillutla \& Murnighan, 1996). In an investigation of expressed anger, Van Dijk, Van Kleef, Steinel, and Van Beest (2008) found that when a counterpart sent a message that expressed anger instead of happiness, people were more likely to send that counterpart incorrect information about the resources available in an ultimatum game.

Surprisingly, no prior research has directly linked feeling angry with deception. This is a surprising omission, because anger is frequently experienced in the workplace in general (Glomb, 2002; Pearson \& Porath, 2005) and in negotiations in particular (Van Kleef, De Dreu, \& 
Manstead, 2004; Yip \& Schweinsberg, 2016). In our investigation, we establish a link between feeling angry and deception.

By investigating how anger promotes deception, we substantially develop our understanding of both emotion and ethical decision-making. Across four experiments, we demonstrate that incidental anger, anger triggered by an unrelated source, promotes deception. We also find that feelings of empathy mediate the relationship between anger and deception. We find that anger reduces empathy, which in turn, increases self-serving deception. We also find that incentives moderate the relationship between anger and deception. Collectively, our studies advance our understanding of anger and the psychology of deception.

\section{Deception}

We focus our investigation on self-serving deception, lies that advantage the deceiver at the expense of the target (Erat \& Gneezy, 2012; Levine \& Schweitzer, 2014). Self-serving lies represent a quintessential form of unethical behavior (Gino, Schweitzer, Mead, \& Ariely, 2011; Tenbrunsel \& Smith-Crowe, 2008), and a growing literature has identified key factors that influence self-serving deception (e.g., O’Connor \& Carnevale, 1997; Schweitzer, DeChurch, \& Gibson, 2005).

When telling a self-serving lie, deceivers navigate the tension between pursuing their self-interest and harming others. To do this, individuals weigh the potential costs and benefits for themselves (Lewicki, 1983; Loewenstein, Cain, \& Sah, 2011) and their counterparts (Gneezy, 2005). Emotions may influence these calculations (Fulmer \& Barry, 2009).

In fact, anger promotes a focus on rewards (Aarts, Ruys, Veling, Renes, de Groot, van Nunen, \& Geertjes, 2010). Within the context of self-serving deception, rewards reflect selfinterested behavior, and as a result, anger may shift attention toward self-interest. Other research 
suggests that anger may shift attention away from caring about others. For example, anger promotes punishment (Fox \& Spector, 1999; Wang et al., 2011), retaliation (Bushman, 2002), and a tendency to rely on stereotypes (Bodenhausen, Sheppard, \& Kramer, 1994). In negotiations, people who feel angry are less cooperative and less interested in interacting with their counterparts in the future (Allred, Mallozzi, Matsui, \& Raia, 1997). Angry people may be particularly less concerned about harming others. Taken together, we expect anger to lower empathy, and we expect this shift in focus to promote self-serving deception.

\section{Emotion and Deception}

Early work conceptualized ethical decision-making as a cognitive process (Kohlberg, 1969). More recent work, however, has begun to consider the role that emotions play in ethical decision-making (Haidt, 2001; Huebner, Dwyer, \& Hauser, 2009; Pizarro, 2000; Rozin, Lowery, Imada, \& Haidt, 1999). This work has begun to establish a link between emotions and ethical behavior, but scholars have explicitly called for additional research to explore how emotions influence ethical judgment and behavior (Avramova \& Inbar, 2013).

Extant work identifies emotions as a consequence of ethical decision-making (Hutcherson \& Gross, 2011; Mullen \& Skitka, 2006; Rozin, Lowery, Imada, \& Haidt, 1999). For example, unfair ultimatum game offers heightened activity in brain regions associated with emotion (Sanfey, Rilling, Aronson, Nystrom, \& Cohen, 2003) and violations of community standards of fairness elicit anger (Schweitzer \& Gibson, 2008). Similarly, when people’s moral convictions are threatened, people feel angry (Mullen \& Skitka, 2006). Importantly, these feelings can also influence subsequent judgments (Mullen \& Skitka, 2006; Schweitzer \& Gibson, 2008). 
Although several scholars have postulated that emotions are capable of shifting beliefs and behavior (Avramova \& Inbar, 2013; Gaspar \& Schweitzer, 2013; Huebner, Dwyer, \& Hauser, 2009; Wheatly \& Haidt, 2005), surprisingly few empirical studies have directly examined the effects of emotion on ethical behavior (Avramova \& Inbar, 2013). Much of the existing work has focused on envy, guilt, and shame (see Gaspar \& Schweitzer, 2013 and Moore \& Gino, 2013 for a review). For example, envy promotes deception (Gino \& Pierce, 2009; Moran \& Schweitzer, 2008). In prior investigations, when individuals envied their counterparts, they were more likely to deceive them than when they did not envy them. Similarly, shame may promote deception by exacerbating malevolent intentions (Tangney, Stuewig, \& Mashek, 2007) rather than rectifying an underlying problem (Tangney, 1991). Anxiety also increases deception because anxiety makes individuals feel threatened (Kouchaki \& Desai, 2015). In contrast to envy and shame, feelings of guilt can curtail deception (Zhong, 2011). Surprisingly, prior work has overlooked the potential link between feeling anger and ethical decision-making. There is limited empirical evidence demonstrating how emotions determine whether an action is right or wrong. Our investigation fills this gap, and more importantly builds our understanding of how emotions influence ethical judgement and behavior.

\section{Anger}

Anger is a negative-valence emotion that is typically triggered by another person (Dollard, Doob, Miller, Mowrer, \& Sears, 1939; Pillutla \& Murnighan, 1996; Smith \& Ellsworth, 1985). When individuals blame another person for an injustice, an unfair outcome, or their inability to reach a desired objective, they often feel anger (Lazarus, 1991; Porath \& Erez, 2009). Consistent with this conceptualization of anger, prior work has found that people feel angry when they receive an unfair offer (Pillutla \& Murnighan, 1996), are interrupted (Mauss, Evers, 
Wilhelm, \& Gross, 2006), read about immoral verdicts (Mullen \& Skitka, 2006), and experience incivility (Pearson \& Porath, 2005; Porath \& Erez, 2007).

When individuals direct their anger at the offender who treated them unfairly or blocked their goal, they experience directed anger. This anger can prompt individuals to confront, fight or punish the offender (Bushman, 2002; Rozin, Lowery, Imada, \& Haidt, 1999). For example, an employee who is insulted by a co-worker may feel anger toward his or her co-worker, and this anger would inform how the employee interacts with that co-worker. Directed anger reflects the functional nature of emotion (Damasio, 1994).

Anger triggered by one interaction, however, may influence cognition and behavior in an unrelated interaction (Andrade \& Ariely, 2009). For example, the anger an employee feels after a co-worker's insult may influence that employee's interactions with his or her spouse in a completely unrelated setting. This influence of anger is incidental and normatively irrelevant to the decision at hand (Dunn \& Schweitzer, 2005). Individuals who feel anger may carry their feelings from one interaction to a separate, unrelated interaction (Berkowitz, 1989). With incidental emotions, cognitive appraisals may persist beyond the initial emotion-eliciting event (Lerner \& Tiedens, 2006; Yip \& Côté, 2013). Anger can shape the perceptions of subsequent, unrelated situations (Dollard et al., 1939; Lerner \& Keltner 2001; Schwarz \& Clore, 1983; Wiltermuth \& Tiedens, 2011).

The study of incidental anger affords both a conservative and a direct test of the influence of emotion on deception. Unlike incidental anger, directed anger confounds emotion with experience. More specifically, individuals who experience directed anger are likely to be motivated by retribution and not just by the emotional experience. In our investigation, we focus on incidental anger and examine whether incidental anger influences deception. 


\section{Incidental Anger Increases Self-Serving Deception}

We advance the following thesis: incidental anger promotes the use of self-serving deception. The decision to engage in self-serving deception balances concern for oneself (i.e. self-interest) and concern for others (i.e. empathy) (Gneezy, 2005; Levine \& Schweitzer, 2014). The greater concern individuals exhibit for themselves and the lower concern for others, the more deceitful they are likely to be. Conversely, if people exhibit lower concern for themselves and they have higher concern for others, they are more likely to tell the truth. We expect anger to diminish concern for others and disinhibit self-interest, which ultimately promotes self-serving deception.

Extant work suggests that empathy influences unethical behavior. Empathy is the capacity to feel emotional concern about the welfare of another party (Davis, 1983). Pizarro (2000) theorized that empathy sensitizes people about the distress that another person is experiencing, and that a morally-relevant event may be occurring. We reason that when individuals lack empathy, they are less concerned about how their actions impact others. As a result, less empathetic people are more likely to behave unethically because they focus more on the rewards for themselves and pay less attention to the costs for others.

Prior research also supports our proposed link between incidental anger and lower empathy. Frijda (1986) suggested that emotions can direct people's attention towards others for whom they care and away from others. In related work, Pizarro (2000) found that individuals feel less empathy towards others for whom they blame a violation. Importantly, it is precisely when individuals blame others for a violation that they are likely to feel angry. In addition, when people feel angry, they become more likely to perceive negative events as under the control of 
others (Fessler, Pillsworth, \& Flamson, 2004). Taken together, we expect angry people to be more likely to blame others, and we postulate that anger will decrease empathy.

This expectation is related to prior research suggesting that anger facilitates self-interest. For example, there is some evidence that anger energizes individuals and promotes the pursuit of self-interested goals (Aarts et al., 2010; Carver \& Harmon-Jones, 2009). Anger is functional insofar as it enables individuals to attain goals. However, as individuals pursue one salient goal, they may neglect other goals, such as the goal to engage in ethical behavior (Ordonez, Schweitzer, Galinsky, \& Bazerman, 2009; Schweitzer, Ordonez, \& Douma 2004).

Drawing on prior work, we expect angry people to become more self-focused than neutral people (Lerner \& Tiedens, 2006). Prior work investigating the relationship between feeling angry and punishing others has focused on the motive to harm (Lazarus, 1991; Lerner \& Tiedens, 2006; Van Dijk, Van Kleef, Steinel, \& Van Beest, 2008). We suggest a distinct, but related account for why angry people punish - and possibly deceive - others. We expect angry people to care less about the harmful consequences of their deception for others and to care more about the beneficial effects of deception for themselves.

To summarize, when individuals encounter an opportunity to engage in self-serving deception, they confront an opportunity to benefit themselves at the expense of others. We propose that as anger reduces empathy, the calculus of this deception decision process changes in a way that promotes deception. More generally, we expect angry people to become more likely to behave unethically at the expense of others as they pursue their self-interest.

\section{Overview of Present Research}

We conducted four laboratory studies to explore the relationship between incidental anger and deception. In Study 1, we induced incidental anger with an essay feedback task and we 
demonstrate that incidental anger promotes deception. In Study 2, we use a different incidental anger induction, a recall task, and we replicate our findings in Study 1. In this study, we also identify empathy as a mediator. In Study 3, we compare the influence of incidental anger on deception with incidental sadness and neutral emotion. We find that anger increases the use of deception, but sadness, another negative-valence emotion does not. In Study 4, we identify incentives as a moderator of the relationship between anger and deception. Across all four studies, we find that incidental anger promotes self-interested deception - even when the target of deception is unrelated to why they are angry. Compared to when people feel neutral emotion, when people feel angry, they are more likely to engage in deception to pursue self-interested goals, because they care less about how their actions affect others.

\section{Study 1}

In Study 1, we tested our thesis that incidental anger promotes self-interested deception.

\section{Method}

\section{Participants}

We recruited 230 people from a North American university to participate in a behavioral laboratory experiment for a $\$ 10$ show-up fee. We randomly assigned half of the people to be participants and half to be evaluators that helped us induce anger. Of the 115 participants, 7 participants failed the comprehension check twice and were not allowed to complete the experiment. No participants reported being suspicious during the study. The final sample size of participants was 108 ( $M_{\text {age }}=21$ years, $S D_{\text {age }}=2.60$ years; $71 \%$ female).

\section{Procedure}

We began the study with a writing task that both participants and evaluators completed. To induce emotion, we manipulated the feedback participants received. We randomly assigned 
participants to one of two conditions: Incidental Anger or Neutral. After the emotion induction, participants played a modified version of the deception game.

Emotion Induction. We induced either anger or a neutral emotion by providing participants with feedback on an essay they wrote. Within each experimental session, half of the people were participants and half were evaluators. The evaluators read and evaluated essays, but did not complete any other tasks in our study. That is, the 115 evaluators we recruited provided feedback to create a credible anger manipulation, but they did not provide data for our experiment.

At the start of the session, participants and evaluators wrote an essay by hand for five minutes about an inspirational moment in their lives. Once five minutes had passed, an experimenter collected and exchanged all of the essays. We then asked everyone to read and provide handwritten feedback for another person’s essay.

Unbeknownst to the participants, we gave the evaluators special instructions. Each evaluator provided feedback for a single participant. We asked half of the evaluators to provide negative feedback that included a critical summary of the essay and identified specific problems with the essay (e.g., “This essay describes the following events , which I found to be boring/ordinary/stupid”). We asked the other half of the evaluators to provide neutral feedback and include a factual summary of the essay (e.g., "This essay describes the following events .”). We gave participants and evaluators five minutes to provide feedback. We include the complete set of instructions we gave for writing and evaluating essays in Appendix A. By matching each participant with an evaluator, we were able to provide quick, personalized, and handwritten feedback. 
After the feedback portion of the study ended, the experimenter collected the essays with the handwritten feedback and returned each essay to the participant who had authored the essay. Participants had two minutes to read the feedback they received before proceeding to the next task.

We described the next stage of the experiment as a separate study. We administered this stage of the experiment via computer. During this stage of the experiment, we asked Evaluators to complete a filler task. We asked participants to read and make decisions in an Interaction Task.

Interaction Task. In the second half of our study, participants read instructions about a task called the Interaction Task in which they were randomly paired with another participant in the session who did not evaluate their essay. The Interaction Task was a modified version of the Deception Game (Gneezy, 2005; Levine \& Schweitzer, 2014; Zhong, 2011). In this task, we assigned participants to the role of the Sender and we paired them with a confederate Receiver. We presented the Sender with information about two payment options. In OPTION A, the Sender earns $\$ 2$ and the Receiver earns $\$ 1$. In OPTION B, the Sender earns $\$ 1$ and the Receiver earns $\$ 2$. We told the Sender that the Receiver would know that the two options exist, but would not have information about the payoffs for each option.

The Sender then made a decision to send one of two pre-worded messages to the Receiver: a lie (“OPTION A will earn the Receiver more money than OPTION B”) or the truth (“OPTION B will earn the Receiver more money than OPTION A"). Prior to making the decision about which message to send, we informed the Sender that past research has revealed that the Receiver follows the message sent by the Sender $90 \%$ of the time. We also informed the Sender that the identities of the Sender and Receiver would be kept confidential, and that the 
money participants earned would be paid to each participant at the end of session privately in cash.

Every participant had to pass a comprehension check. After completing the comprehension check, participants made a decision to send either an honest or deceptive message. Participants then completed an emotion manipulation check and answered demographic questions. We then debriefed and paid participants.

Measures

Anger Manipulation Check. After the interaction task, participants rated the extent to which they felt angry, annoyed, irritated, and outraged (Dunn \& Schweitzer, 2005) on a scale ranging from 1 (does not describe my feelings at all) to 7 (describes my feelings very well) $(M=2.62, S D=1.93 ; \alpha=.95)$.

Deception. We recorded whether participants chose to send a deceptive message (scored as 1 ) or a truthful message (scored as 0 ).

\section{Results and Discussion}

Our manipulation of incidental anger was successful. Participants in the incidental anger condition reported higher levels of anger $(M=3.90, S D=1.90)$ than did those in the neutral condition $(M=1.34, S D=.80), t(106)=-9.15, p<.001$.

Supporting our thesis, participants in the incidental anger condition were more likely to deceive their counterparts (82\%) than were those in the neutral condition (61\%), $\chi^{2}(1, N=$ 108) $=5.48, p=.019, \Phi=.23$ (see Figure 1). This finding supports our thesis. Compared to feeling neutral emotion, incidental anger increased deception.

In Study 1, we establish a link between anger and deception. Angry people were more likely to engage in self-serving deception than were neutral people. 


\section{Study 2}

In Study 2, we extend our investigation to explore the role of empathy in mediating the influence of incidental anger on deception. We postulate that anger promotes deception by causing individuals to become less empathetic.

We also extend our investigation by employing a different emotion induction and a different measure of deception. To induce emotion, we used a writing recall task (e.g., Dunn \& Schweitzer, 2005; Lerner \& Keltner, 2001; Strack, Schwarz, \& Gschneidinger, 1985), rather than the essay-feedback task we used in Study 1. To measure deception, we assessed whether or not participants recommend an unpleasant tasting beverage. Participants could earn a bonus payment for misleading their counterpart about the beverage.

\section{Pilot Study}

Before we conducted our main study, however, we conducted a pilot study to link incidental anger with empathy. We conducted our pilot study with an online panel of adult participants on Amazon Mechanical Turk. Our sample consisted of 84 participants $\left(M_{\text {age }}=35\right.$ years, $S D_{\text {age }}=12.95$ years; $52 \%$ female).

As in Study 1, we asked participants in the pilot study to write an essay about an inspirational moment in their lives. We randomly assigned participants to one of two betweenparticipants conditions: Incidental Anger vs. Neutral. Similar to Study 1, participants in the Anger condition received negative, critical feedback. Participants in the Neutral condition received neutral, factual feedback. We provided the same critical feedback to all participants in the Anger condition and the same factual feedback to all participants in the Neutral condition. We include the feedback that we presented to participants in Appendix B. 
To measure empathy, we asked participants to complete a measure that we adapted from Davis (1983); $M=5.25, S D=1.23, \alpha=.80$. Our empathy measure is presented in Appendix C. In this study, we explore whether or not anger decreases empathy.

Supporting our thesis, we found that participants in the anger condition reported lower levels of empathy $(M=4.85, S D=1.46)$ than did participants in the neutral condition $(M=5.59$, $S D=.89), t(80)=2.78, p=.007$. These findings reveal that compared to people who feel neutral emotion, people who feel angry care less about others.

\section{Method}

\section{Participants}

We recruited 184 students from a large North American university to participate in this study. We lost data from six participants because of a technical glitch with our instant messaging platform and three participants indicated suspicion. The final sample included 175 students ( $M_{\text {age }}=21$ years, $S D_{\text {age }}=2.40$ years; $72 \%$ female $)$.

Procedure

As in Study 1, we informed participants that they would complete separate studies in the same session. We randomly assigned participants to either an incidental anger condition or a neutral condition. We manipulated emotion by having participants complete a writing recall task (Strack, Schwarz, \& Gschneidinger, 1985). Participants in the incidental anger condition described a situation that made them the most angry they have ever felt in their lives. Participants in the neutral condition described how they spend a typical evening.

After completing the emotion induction, participants proceeded to a purportedly unrelated cola beverage taste task. We conducted this part of the experiment via an instant messaging platform. In this task, we assigned participants to the role of advisor and we paired 
them with a confederate who we assigned to the role of taster. We informed participants that the taster would need to choose one beverage to taste among four beverages labelled A, B, C, or D. We gave participants in the advisor role information about how each beverage tasted. We told advisors that this information would not be available to the tasters. This information took the form of comments from an earlier pilot study. Three of the beverages (A, C, and D) had comments indicating that they were pleasant tasting (e.g., "Very subtle, smooth.”, “There’s a cherry-ish note, I like that one.”). However, one beverage (Beverage B) was described as having an unpleasant taste (e.g., “That tasted like it had ammonia in it.”).

We provided participants with incentives. Specifically, we told participants that as advisors they would receive $\$ 1$ in addition to the standard show-up fee if they could persuade the taster to drink beverage B. To enhance credibility, we arranged 16 cups filled with cola organized in four rows on a table near the door of the behavioral lab. Every participant saw the cups filled with cola as they entered the behavioral laboratory. After being seated, we pulled a screen to partition the room in half.

We then asked participants to send messages to their counterpart (the taster) using an instant messaging platform. The instant messaging platform was designed so that the confederate taster would send the first message, the participant advisor would send the second message, and the two parties could continue sending messages. The confederate taster adhered to scripted messages throughout the chat and started the chat by asking the advisor which beverage they would recommend. We include the script for the confederate taster in Appendix D. We assessed deception by recording whether the advisor recommended the unpleasant tasting beverage (Beverage B) or recommended one of the pleasant tasting beverages (A, C, or D). 
After the beverage taste task, participants completed an empathy measure followed by an emotion manipulation check and demographic questions. In each emotion condition, we counterbalanced whether the empathy measure was presented before the beverage taste task or after the beverage taste task.

Measures

Anger Manipulation Check. After the beverage taste task, participants rated the extent to which they felt angry, annoyed, irritated, and outraged on a scale ranging from 1 (does not describe my feelings at all) to 7 (describes my feelings very well) $(M=3.42, S D=2.39 ; \alpha=.91)$.

Empathy. We adapted five items from the interpersonal reactivity index that assessed other-oriented feelings of concern towards unfortunate others (Davis, 1983). Participants rated each item (e.g., “I felt concerned for people less fortunate than me.”) on a scale ranging from 1 (does not describe me at all) to 7 (describes me very well) $(M=5.15, S D=1.07 ; \alpha=.71)$. We include the complete scale that we used in Appendix C.

Deception. We recorded whether participants deceived their counterpart by recommending beverage $\mathrm{B}$ (scored as 1 ) or were truthful to their counterpart by recommending beverage $\mathrm{A}, \mathrm{C}$, or $\mathrm{D}$ (scored as 0 ).

\section{Results}

As expected, participants in the incidental anger condition $(M=5.25, S D=1.91)$ reported higher levels of anger than did those in the neutral condition $(M=1.52, S D=.87), t(171)=-16.42$, $p<.001$.

To test our thesis, we conducted a binary logistic regression. We find similar results with a chi-square test for independence because the dependent variable consisted of a binary decision to deceive (recommend beverage B) or tell the truth (recommend beverage A, C, or D). We 
found that participants in the incidental anger condition were more likely to deceive their counterpart (82\%) than were participants in the neutral condition (52\%), $\beta=.40, S E=.35$, Wald(1)=17.33, $p<.001, \Phi=.32$. Using binary logistic regression analysis, we found no significant effect for order (whether the empathy measure was presented before the beverage task or after the beverage task) on deception, $\beta=.27, S E=.32$, Wald(1)=.70, $p=.404$. We also found no significant effect for the interaction between the emotion condition and order, $b=-.79, S E=.72$, Wald(1)=1.21, $p=.271$.

We tested whether empathy mediates the effect of incidental anger on deception by employing the indirect bootstrapping technique (Preacher \& Hayes, 2008). As recommended by Zhao, Lynch, and Chen (2010), we performed 10,000 bootstrap resamples using Preacher and Hayes’s (2008) SAS macro. Our analysis revealed that incidental anger had an indirect effect on deception through empathy $(b=.18,95 \%$ confidence interval $[\mathrm{CI}]=.019, .432)$. Because the biascorrected 95\% confidence interval did not include zero, we conclude that empathy mediates the effect of incidental anger on deception.

In Study 2, we find that when people feel angry, they become more likely to engage in deception and that reduced empathy mediates this relationship.

\section{Study 3}

In Study 3, we extend our investigation of the link between anger and deception by contrasting anger with another negative-valence emotion, sadness. Sadness is a negative-valence emotion associated with greater risk-taking (Raghunathan \& Pham, 1999), a greater focus on the present (Lerner, Li, \& Weber, 2012), and more systematic thinking (Tiedens \& Linton, 2001). Prior studies have found that similarly valenced emotions, such as fear, anger, and sadness, influence attitudes and behavior very differently. That is, even though emotions are similar in 
valence, they are distinct from each other along other dimensions or "appraisal tendencies" (Raghunathan \& Pham, 1999; Wiltermuth \& Tiedens, 2011). For example, when people feel angry, they become more likely to blame someone else (other-person control). In contrast, when people feel sad, they become more likely to blame the situation (situational control) (Keltner, Ellsworth, \& Edwards, 1993; Smith \& Ellsworth, 1985).

We do not expect negative-valence to promote deception. Rather, we expect anger to uniquely promote deception, because anger is likely to decrease concern for others. In contrast, sadness may cause people to engage in systematic thinking (Tiedens \& Linton, 2001) and remain concerned about the potential harm that their actions may cause others. Taken together, we expect that incidental anger promotes self-serving deception compared to incidental sadness and neutral emotion.

\section{Method}

\section{Participants}

We recruited 190 students at a large North American university for a $\$ 10$ show-up fee. Eleven participants failed the comprehension check twice for the interaction task and, therefore, did not complete the study. Our final sample consisted of 179 participants ( $M_{\mathrm{age}}=22$ years, $S D_{\text {age }}=4.92$ years; $57 \%$ female).

\section{Procedure}

We randomly assigned participants to one of three conditions: Incidental Anger, Incidental Sadness, or Neutral Emotion. To manipulate emotions, we had participants watch emotion-inducing video clips (Gross \& Levenson, 1995). Specifically, participants in the incidental anger condition watched a video clip of a woman yelling racial epithets at a convenience store clerk. Participants in the incidental sadness condition watched a video clip 
from the cartoon movie, Up; in this clip, participants watch a husband and wife grow old and see the husband's wife pass away. Participants in the neutral condition watched a video clip from a National Geographic documentary about ocean life. All video clips are available upon request from the authors.

After watching the video, we asked participants to describe the video in one sentence, rate the resolution quality and rate the sound quality of the video. These questions misdirect participants so that they could be less likely to attribute their feelings to the video clips.

Participants then continued to a purportedly unrelated study, which we called the Interaction Task. We used the same paradigm to measure deception as we did in Study 1. . However, we presented different payment options to the Sender than we did in Study 1. In OPTION A, the Sender earns \$1.50 and the Receiver earns \$1.25. In OPTION B, the Sender earns \$1.25 and the Receiver earns \$1.50. We assessed whether participants sent a deceitful message or truthful message to their confederate counterpart.

Following the Interaction Task, participants completed an emotion manipulation check and answered some demographic questions. We then debriefed and paid participants.

\section{Measures}

Emotion Manipulation Check. After the Interaction Task, participants rated the extent to which they felt different emotions on a scale ranging from 1 (does not describe my feelings at all) to 7 (describes my feelings very well). We measured anger by averaging responses for angry, irritated, and annoyed $(M=2.72, S D=2.08 ; \alpha=.97)$. We measured sadness by averaging responses for sad, down, and gloomy ( $M=3.11, S D=1.73 ; \alpha=.90)$. We measured neutral emotion by averaging responses for indifferent, neutral, and calm $(M=3.12, S D=1.55 ; \alpha=.74)$. 
Deception. We assessed whether participants chose to send a deceitful message (scored as 1 ) or a truthful message (scored as 0 ).

\section{Results and Discussion}

Our emotion induction was effective. We found that participants reported higher levels of anger in the incidental anger condition $(M=4.97, S D=1.79)$ than participants in the sadness condition $(M=1.21, S D=.53)$ or the neutral condition $(M=1.90, S D=1.17), F(2,176)=148.44$, $p<.001$. We report results for the emotion manipulation checks in Table 1.

As predicted, participants in the incidental anger condition were more likely to deceive others (77\%) than were those in the sadness condition (54\%) and the neutral condition (61\%), $\chi^{2}(2, N=179)=7.19, \mathrm{p}=.027, \Phi=.20$.

We conducted separate chi-square tests to compare the influence of emotions on deception. As found in our previous studies, participants in the anger condition were more likely to engage in deception than were participants in the neutral condition, $\chi^{2}(1, N=120)=3.65$, $\mathrm{p}=.057, \Phi=.17$. We also find that participants in the anger condition were more likely to deceive others than were those in the sadness condition, $\chi^{2}(1, N=120)=6.94, p=.008, \Phi=.24$. There was no difference in deception between participants in the neutral condition and sadness condition, $\chi^{2}(1, N=118)=.56, \mathrm{p}=.456, \Phi=.07$.

We find that negative-valence alone does not have an effect on unethical behavior. We demonstrate that incidental anger has a unique influence on deception that is separate from another negative-valence emotion, sadness.

\section{Study 4}

When individuals engage in self-interested acts of deception, they derive gains at the expense of others. In Study 2, we find that anger diminishes empathy for others and disinhibits 
selfish deceptive behavior. In Studies 1, 2 and 3, self-interested acts of deception benefited the deceiver and harmed the target. Though self-interested acts of deception typically harm targets, in this study, we disentangle benefits to the self from harm to others. That is, in Study 4, we extend our investigation of anger and deception by considering the moderating role of incentives, and investigate whether or not anger promotes deception when deceptive acts do not benefit the deceiver.

We expect incidental anger to promote deception when deceivers benefit at the expense of others. However, when deceivers cannot derive benefits from deception, we do not expect anger to promote deception. That is, in this study, we investigate whether anger promotes deception by diminishing empathy and disinhibiting self-interested behavior (as we propose) or anger promotes vengeful behavior even when the deceiver cannot profit from deception. Though prior work has found that anger triggered by unfair offers increase rejection rates (Pillutla \& Murnighan, 1996; Turillo, Folger, Lavelle, Umphress, \& Gee, 2002), these findings reflect directed anger that confounds retaliation and relational concerns with anger.

\section{Method}

Participants

We recruited 218 participants at a North American university. We excluded eight participants who expressed suspicion and we report the results from 210 participants $\left(M_{\text {age }}=20\right.$ years, $S D_{\text {age }}=1.55$ years; $61 \%$ female).

\section{Procedure}

We randomly assigned participants to one of four between-participant conditions from a 2(Emotion: Incidental Anger vs. Neutral) $\times$ 2(Incentive: \$1 vs. \$0) design. In this experiment, we manipulated emotion by having participants complete the same writing recall task we used in 
Studies 2 and 3. Participants in the incidental anger condition spent five minutes writing about a situation that made them angry. Participants in the neutral condition spent five minutes to write about how they spend a typical evening.

After the emotion induction, we administered the same cola beverage taste task that we used in Study 2. We assessed deception by recording whether participants recommended the unpleasant tasting beverage (Beverage B) or recommended one of the pleasant tasting beverages (A, C, or D). In the incentive condition, we told participants that they would receive a $\$ 1$ bonus if they persuaded their counterpart to drink beverage B. In the no incentive condition, we did not give participants any information about a bonus. The study was otherwise identical to Study 2. Measures

Anger Manipulation Check. At the end of the experiment, participants rated the extent to which they felt angry, annoyed, irritated, and outraged on a scale ranging from 1 (does not describe my feelings at all) to 7 (describes my feelings very well) $(M=3.12, S D=2.36 ; \alpha=.90)$.

Deception. We recorded whether participants chose to deceive their counterpart by recommending beverage $\mathrm{B}$ (scored as 1 ) or chose to recommend beverage $\mathrm{A}, \mathrm{C}$, or D (scored as $0)$.

\section{Results}

As we expected, participants in the incidental anger condition $(M=4.80, S D=2.13)$ reported higher levels of anger than did those in the neutral condition $(M=1.46, S D=1.01)$, $t(208)=-14.57, p<.001$.

To test our hypothesis, we planned to conduct a binary logistic regression. Specifically, we planned to regress deception on emotion condition, incentive condition, and their interaction. However, the maximum likelihood estimate did not exist because none of the participants in the 
no incentive condition chose to deceive. As a result, we conducted separate chi-square tests for participants within the incentive condition and for participants within the no incentive condition. As in Studies 1, 2, and 3, when participants received \$1 for deceiving the taster, participants in the incidental anger condition were more likely to deceive their counterpart (80\%) than were those in the neutral condition (62\%), $\chi^{2}(1, N=102)=4.18, \mathrm{p}=.041, \Phi=.20$ (see Figure 2 ). By contrast, when participants received no incentive for deceiving their counterpart, none of the participants in the incidental anger condition or the neutral condition deceived their counterpart.

Compared to feeling neutral emotion, feeling incidental anger increases deception-but only when the deceiver benefits from deception. We find that the relationship between anger and deception is moderated by financial incentives. When feeling angry, individuals are more likely to pursue their self-interest at the expense of others. However, when individuals cannot gain by harming others, anger does not promote deception.

\section{General Discussion}

Anger promotes deception. Across four studies, we find that individuals who experience incidental anger are more likely to deceive a counterpart than those in a neutral state. We find that empathy mediates the relationship between incidental anger and deception. Angry individuals are less empathetic, and as a result, angry individuals care less than neutral individuals about the harmful consequences of their self-interested actions.

We contrasted the influence of anger with the influence of sadness on deception. We found that people who feel anger are more likely to deceive their counterparts than are people who feel sadness. This suggests that the link between anger and deception cannot be explained by the appraisals of negative-valence alone. Instead, anger, which is characterized by both negative-valence and other-person control, exerts a unique influence of deception. 
Finally, we identify incentives as a boundary condition of the effect of incidental anger on deception. By testing the moderating role of incentives, we disentangle the motivation to harm others from the motivation to pursue self-interest. Our findings suggest that rather than motivating people to harm others, anger curtails empathy and disinhibits people to pursue their self-interest.

Across our studies, we obtain a consistent pattern of results linking incidental anger and deception. This was true across different emotion inductions and different measures of deception. Theoretical Implications

Our findings significantly advance our theoretical understanding of deception. Though some prior research has conceptualized deception as a cognitive process (Lewicki, 1983; Moore \& Tenbrunsel, 2014), recent research demonstrates that the deception decision process is also influenced by emotions such as envy (Gino and Pierce, 2009; Moran \& Schweitzer, 2008). Prior research, however, has overlooked the role of anger in deception, despite the fact that anger is frequently encountered in the workplace (Pearson \& Porath, 2005; Wang, Liao, Zhan, \& Shi, 2011) and in domains such as negotiation (Van Kleef, De Dreu, \& Manstead, 2004) where the influence of anger on deception may pose a significant challenge.

Our work directly extends our understanding of the behavioral consequences of anger. Prior studies have shown that anger promotes a range of behaviors from punishment to less careful thinking (Harmon-Jones, Schmeichel, Mennitt, \& Harmon-Jones, 2011; Porath \& Erez, 2009; Tiedens \& Linton, 2001; Wang, Liao, Zhan, \& Shi, 2011), but the relationship between anger and unethical behavior has remained an open question. We demonstrate that anger promotes deception because when people feel angry, they become particularly motivated to engage in self-interested behavior. 
Our research is the first to demonstrate that anger reduces empathy. We find a significant association between feeling angry and experiencing less empathy for others. Lower levels of empathy explain why angry people are more likely to deceive others.

Our findings linking anger with unethical behavior contribute to the literature on emotions and ethical behavior. A growing literature reveals that emotions can influence moral judgments, but the conceptualization of emotions as causal has received limited empirical examination (Avramova \& Inbar, 2013). Our results directly address this call.

In addition, our findings contribute to the negotiation literature that has studied anger. Several scholars have identified benefits of expressing anger within a negotiation; displays of anger can elicit concessions (Keltner \& Haidt, 1999; Van Kleef, De Dreu, \& Manstead, 2004). Our work identifies an important drawback to expressing anger. Individuals who express anger are likely to elicit anger in counterparts (Hatfield, Cacioppo, \& Rapson, 1993). In light of our findings, we postulate that expressing anger will increase the likelihood that a counterpart will engage in deception. This suggests that negotiators should be particularly wary of employing strategic displays of anger.

Our work also makes a methodological contribution. We introduce a novel method to induce anger. In Study 1, we employed an inspirational essay writing task in which evaluators provided critical feedback. In contrast to prior work that has elicited anger with writing recall tasks (Strack, Schwarz, \& Gschneidinger, 1985), film clips (Gross \& Levenson, 1995) or music (Sutherland, Newman, \& Rachman, 1982), our method is personal and meaningful. Though expensive in terms of participant time, we highlight two primary benefits of this induction method. First, this induction enhances realism within a laboratory setting. When we administered this task on paper, no participant indicated suspicion that their counterpart was not another 
participant. Second, this anger induction method affords a personalized induction that can be administered in groups.

\section{Limitations and Future Directions}

Several limitations of our work identify directions for future research. First, we report results from controlled experiments in a laboratory. This approach strengthens the internal validity of our findings, but future work should extend our investigation to field settings. Anger is commonly experienced in organizations (Glomb, 2002), and future research is needed to explore the association between anger and unethical behavior in organizations. In practice, incivility may evoke anger and elicit unethical behavior.

Second, we used two-person economic interactions and social interactions to measure deception. This approach afforded experimental control and presented participants with a clear choice between telling the truth and lying. Our participants, however, did not interact face-toface, and we did not create opportunities for a broader set of deceptive behaviors such as lies of omission or prosocial lies. Future research should explore the influence of anger on a broader set of deceptive behaviors and in more complex interactions.

Third, our research focused on incidental anger. Incidental anger is normatively irrelevant and should not influence behavior in a separate interaction. As a result, the study of incidental anger affords a conservative test of the influence of anger. We suspect that the rate of deception would be higher when dealing with someone who had directly offended the decision-maker. Moral self-righteousness may strengthen the relationship between anger and deception. Future research should examine interactions in which anger is generated by the counterpart.

Fourth, we examined the influence of incidental anger on deception in relation to another negative-valence emotion, sadness. We found that anger increases deception, whereas sadness 
does not influence deception. Anger is characterized by negative-valence and other-person control. When angry individuals feel negatively about a situation, they often perceive someone else to be responsible (Smith \& Ellsworth, 1985). The combination of negative-valence and blaming others decreases concern for other people that can be harmed by self-interested deception. Future research should explore emotions that promote self-focus. Pride is a positivevalence emotion that is associated with high personal control. Future research should explore the link between pride and ethical decision-making.

\section{Conclusion}

Anger promotes deception. When individuals feel angry, they are more likely to deceive others. We find that angry individuals are less concerned about the welfare of others, and consequently more likely to exhibit self-interested unethical behavior. Across our studies, we link incidental anger to self-serving deception. By focusing on incidental anger, we isolate how feeling anger influences deception from seeking retribution. We suspect that the link between directed anger and deception will be even greater. We urge leaders, managers, and employees to recognize that, in our angry moments, we may lose our moral compass. 


\section{References}

Aarts, H., Ruys, K. I., Veling, H., Renes, R. A., de Groot, J. H., van Nunen, A. M., \& Geertjes, S. (2010). The art of anger: Reward context turns avoidance responses to anger-related objects into approach. Psychological Science, 21(10), 1406-1410.

Allred, K. G., Mallozzi, J. S., Matsui, F., \& Raia, C. P. (1997). The influence of anger and compassion on negotiation performance. Organizational Behavior and Human Decision Processes, 70(3), 175-187.

Andrade, E. B., \& Ariely, D. (2009). The enduring impact of transient emotions on decision making. Organizational Behavior and Human Decision Processes, 109, 1-8.

Avramova, Y. R., \& Inbar, Y. (2013). Emotion and moral judgment. Wiley Interdisciplinary Reviews: Cognitive Science, 4(2), 169-178.

Barry, B., \& Oliver, R. L. (1996). Affect in dyadic negotiation: A model and propositions. Organizational Behavior and Human Decision Processes, 67(2), 127-143.

Berkowitz, L. (1989). Frustration-aggression hypothesis: Examination and reformulation. Psychological Bulletin, 106, 59-73.

Bodenhausen, G. V., Sheppard, L. A., \& Kramer, G. P. (1994). Negative affect and social judgment: The differential impact of anger and sadness. European Journal of social psychology, 24(1), 45-62.

Bushman, B. J. (2002). Does venting anger feed or extinguish the flame? Catharsis, rumination, distraction, anger, and aggressive responding. Personality and Social Psychology Bulletin, 28, 724-731.

Carver, C. S., \& Harmon-Jones, E. (2009). Anger is an approach-related affect: evidence and implications. Psychological bulletin, 135(2), 183. 
Coalition Against Insurance Fraud. (2012). Coalition Against Insurance Fraud Annual Report (CAIF, Washington, DC).

Damasio, A. R. (1994). Descartes' error: Emotion, reason, and the human brain. New York: G.P. Putnam.

Davis, M. H. (1983). Measuring individual differences in empathy: Evidence for a multidimensional approach. Journal of Personality and Social Psychology, 44(1), 113126.

Dollard, J., Doob, L. W., Miller, N. E., Mowrer, O. H., \& Sears, R. R. (1939). Frustration and aggression. New Haven, CT: Yale University Press.

Dunn, J. R., \& Schweitzer, M. E. (2005). Feeling and believing: The influence of emotion on trust. Journal of Personality and Social Psychology, 88(5), 736-748.

Erat, S., \& Gneezy, U. (2012). White lies. Management Science, 58(4), 723-733.

Fessler, D. M. T., Pillsworth, E. G., \& Flamson, T. J. (2004). Angry men and disgusted women: An evolutionary approach to the influence of emotions on risk taking. Organizational Behavior and Human Decision Processes, 95, 107-123.

Fox, S., \& Spector, P. E. (1999). A model of work frustration-aggression. Journal of organizational behavior, 20(6), 915-931.

Frijda, N. H. (1986). The emotions. London: Cambridge University Press.

Fulmer, I. S., \& Barry, B. (2009). Managed hearts and wallets: Ethical issues in emotional influence by and within organizations. Business Ethics Quarterly, 19(2), 155-191.

Gaspar, J. P., \& Schweitzer, M. E. (2013). The emotion deception model: A review of deception in negotiation and the role of emotion in deception. Negotiation and Conflict Management Research, 6(3), 160-179. 
Gino, F., \& Pierce, L. (2009). Dishonesty in the name of equity. Psychological Science, 20(9), 1153-1160.

Gino, F., \& Pierce, L. (2010). Lying to level the playing field: Why people may dishonestly help or hurt others to create equity. Journal of Business Ethics, 95(1), 89-103.

Gino, F., Schweitzer, M. E., Mead, N. L., \& Ariely, D. (2011). Unable to resist temptation: How self-control depletion promotes unethical behavior. Organizational Behavior and Human Decision Processes, 115(2), 191-203.

Gino, F., \& Shea, C. (2012). Deception in negotiations: The role of emotions. In R. Croson \& G. Bolton (Eds.), Handbook of Conflict Resolution. Oxford University Press.

Glomb, T. M. (2002). Workplace anger and aggression: Informing conceptual models with data from specific encounters. Journal of Occupational Health Psychology, 7(1), 20-36.

Gneezy, U. (2005). Deception: The role of consequences. The American Economic Review, 95(1), 384-394.

Gross, J. J., \& Levenson, R. W. (1995). Emotion elicitation using films. Cognition and Emotion, 9(1), 87-108.

Haidt, J. (2001). The emotional dog and its rational tail: a social intuitionist approach to moral judgment. Psychological review, 108(4), 814.

Harmon-Jones, C., Schmeichel, B. J., Mennitt, E., \& Harmon-Jones, E. (2011). The expression of determination: Similarities between anger and approach-related positive affect. Journal of Personality and Social Psychology, 100(1), 172-181.

Hatfield, E., Cacioppo, J. L. \& Rapson, R. L. (1993). Emotional contagion. Current Directions in Psychological Sciences, 2, 96-99. 
Huebner, B., Dwyer, S., \& Hauser, M. (2009). The role of emotion in moral psychology. Trends in Cognitive Sciences, 13, 1-6.

Hutcherson, C. A., \& Gross, J. J. (2011). The moral emotions: A social-functionalist account of anger, disgust, and contempt. Journal of personality and social psychology, 100(4), 719.

Keltner, D., Ellsworth, P. C., \& Edwards, K. (1993). Beyond simple pessimism: effects of sadness and anger on social perception. Journal of personality and social psychology, 64(5), 740.

Keltner, D., \& Haidt, J. (1999). Social functions of emotions at multiple levels of analysis. Cognition and Emotion, 13, 505-522.

Kohlberg, L. (1969). Stage and sequence: The cognitive-developmental approach to socialization.

Kouchaki, M., \& Desai, S. D. (2015). Anxious, threatened, and also unethical: How anxiety makes individuals feel threatened and commit unethical acts. Journal of Applied Psychology, 100(2), 360.

Lazarus, R.S. (1991). Emotion and adaptation. Oxford, UK: Oxford University Press.

Lerner, J. S., \& Keltner, D. (2001). Fear, anger, and risk. Journal of Personality and Social Psychology, 81(1), 146-159.

Lerner, J. S., Li, Y., \& Weber, E. U. (2012). The financial costs of sadness. Psychological Science, 24, 72-79.

Lerner, J. S., \& Tiedens, L. Z. (2006). Portrait of the angry decision maker: How appraisal tendencies shape anger’s influence on cognition. Journal of Behavioral Decision Making, 19, $115-137$. 
Levine, E. E., \& Schweitzer, M. E. (2014). Are liars ethical? On the tension between benevolence and honesty. Journal of Experimental Social Psychology, 53, 107-117.

Lewicki, Roy J. (1983). Lying and deception: A behavorial model, with application to negotiation. In M. H. Bazerman \& R. J. Lewicki (Eds.), Negotiation in organizations (pp. 68 -90). Beverly Hills: Sage Publication.

Loewenstein, G., Cain, D., \& Sah, S. (2011). The limits of transparency: Pitfalls and potential of disclosing conflicts of interest. American Economic Review; Paper and Proceedings, 101(3), 423-428.

Lount, R. B. Jr., Zhong, C., Sivanathan, N., \& Murnighan, J. K. (2008). Getting off on the wrong foot: The timing of a breach and the restoration of trust. Personality and Social Psychology Bulletin, 34(12), 1601-1612.

Mauss, I. B., Evers, C., Wilhelm, F. H., \& Gross, J. J. (2006). How to bite your tongue without blowing your top: Implicit evaluation of emotion regulation predicts affective responding to anger provocation. Personality and Social Psychology Bulletin, 32(5), 1-14.

Moore, C., \& Gino, F. (2013). Ethically adrift: How others pull our moral compass from true North, and how we can fix it. Research in Organizational Behavior, 33, 53-77.

Moore, C., \& Tenbrunsel, A. E. (2014). “Just think about it”? Cognitive complexity and moral choice. Organizational Behavior and Human Decision Processes, 123, 138-149.

Moran, S., \& Schweitzer, M. E. (2008). When better is worse: Envy and the use of deception. Negotiation and Conflict Management Research, 1(1), 3-29.

Mullen, E., \& Skitka, L. J. (2006). Exploring the psychological underpinnings of the moral mandate effect: Motivated reasoning, group differentiation, or anger? Journal of Personality and Social Psychology, 90(4), 629-643. 
O'Connor, K. M., \& Carnevale, P. J. (1997). A nasty but effective negotiation strategy: Misrepresentation of a common-value issue. Personality and Social Psychology Bulletin, 23(5), 504-515.

Olekalns, M., \& Smith, P. L. (2009). Mutually dependent: Power, trust, affect and the use of deception in negotiation. Journal of Business Ethics, 85, 347-365.

Ordóñez, L. D., Schweitzer, M. E., Galinsky, A. D., \& Bazerman, M. H. (2009). Goals gone wild: The systematic side effects of overprescribing goal setting. The Academy of Management Perspectives, 23(1), 6-16.

Pearson, C. M., \& Porath, C. L. (2005). On the nature, consequences and remedies of workplace incivility: No time for “nice”? Think again. Academy of Management Executive, 19(1), 718.

Pillutla, M. M., \& Murnighan, J. K. (1996). Unfairness, anger, and spite: Emotional rejections of ultimatum offers. Organizational Behavior and Human Decision Processes, 68(3), 208224.

Pitesa, M., \& Thau S. (2013). Compliant sinners, obstinate saints: How power and self-focus determine the effectiveness of social influences in ethical decision making. Academy of Management Journal, 56(3), 635-658.

Pizarro, D. (2000). Nothing more than feelings? The role of emotions in moral judgment. Journal for the Theory of Social Behavior, 30, 355-375.

Porath, C. L. \& Erez, A. (2007). Does rudeness really matter? The effects of rudeness on task performance and helpfulness. Academy of Management Journal, 50(5), 1181-1197. 
Porath, C. L., \& Erez, A. (2009). Overlooked but not untouched: How rudeness reduces onlookers’ performance on routine and creative tasks. Organizational Behavior and Human Decision Processes, 109, 29-44.

Preacher, K. J., \& Hayes, A. F. (2008). Asymptotic and resampling strategies for assessing and comparing indirect effects in multiple mediator models. Behavior Research Methods, 40, 879-891.

Raghunathan, R., \& Pham, M. T. (1999). All negative moods are not equal: Motivational influences of anxiety and sadness on decision making. Organizational behavior and human decision processes, 79(1), 56-77.

Rozin, P., Lowery, L., Imada, S., \& Haidt, J. (1999). The CAD triad hypothesis: A mapping between three moral emotions (contempt, anger, disgust) and three moral codes (community, autonomy, divinity). Journal of Personality and Social Psychology, 76(4), 574-586.

Sanfey, A., Rilling, J., Aronson, J. A., Nystrom, L. E., \& Cohen, J. D. (2003). The neural basis of economic decision-making in the ultimatum game. Science, 5626, 1755-1758.

Schwarz, N., \& Clore, G. L. (1983). Mood, misattribution, and judgments of well-being: Informative directive functions of affective states. Journal of Personality and Social Psychology, 45(3), 513-523.

Schweitzer, M., DeChurch, L., \& Gibson, D. (2005). Conflict frames and the use of deception: Are competitive negotiators less ethical? Journal of Applied Social Psychology, 35(10), 2123-2149. 
Schweitzer, M., \& Gibson, D. (2008). Fairness, feelings, and ethical decision-making:

Consequences of violating community standards of fairness. Journal of Business Ethics, 77(3), 287-301.

Schweitzer, M., Ordonez, L. \& Douma, B. (2004). Goal setting as a motivator of unethical behavior. Academy of Management Journal, 47(3), 422-432.

Smith, C., Ellsworth, P. (1985). Patterns of Cognitive Appraisal in Emotion. Journal of Personality and Social Psychology, 48(4), 813-838.

Strack, F., Schwarz, N., \& Gschneidinger, E. (1985). Happiness and reminiscing: The role of time perspective, mood, and mode of thinking. Journal of Personality and Social Psychology, 49, 1460-1469.

Sutherland, G., Newman, B. \& Rachman, S. (1982). Experimental investigations of therelations between mood and intrusive, unwanted cognitions. British Journal of Medical Psychology, 55, 127-138.

Tangney, J. P. (1991). Moral affect: The good, the bad, and the ugly. Journal of Personality and Social Psychology, 59, 102-111.

Tangney, J. P., Stuewig, J., \& Mashek, D. J. (2007). Moral emotions and moral behavior. Annual Review of Psychology, 58, 345-372.

Tenbrunsel, A. E. (1998). Misrepresentation and expectations of misrepresentation in an ethical dilemma: The role of incentives and temptation. Academy of Management Journal, 41(3), 330-339.

Tenbrunsel, A. E., \& Smith-Crowe, K. (2008). Ethical decision making: Where we've been and where we're going. The Academy of Management Annals, 2(1), 545-607. 
Tiedens, L. Z., Linton, S. (2001). Judgment under emotional certainty and uncertainty: The effects of specific emotions on information processing. Journal of Personality and Social Psychology, 81(6), 973-988.

Turillo, C. J., Folger, R., Lavelle, J. J., Umphress, E. E., \& Gee, J. O. (2002). Is virtue its own reward? Self-sacrificial decisions for the sake of fairness. Organizational Behavior and Human Decision Processes, 89(1), 839-865.

Van Dijk, E., Van Kleef, G. A., Steinel, W., \& Van Beest, I. (2008). A social functional approach to emotions in bargaining: When communicating anger pays and when it backfires. Journal of Personality and Social Psychology, 94(4), 600-614.

Van Kleef, G. A., De Dreu, C. K. W., \& Manstead, A. S. R. (2004). The interpersonal effects of anger and happiness in negotiations. Journal of Personality and Social Psychology, 86, $57-76$.

Wang, M., Liao, H., Zhan, Y., \& Shi, J. (2011). Daily customer mistreatment and employee sabotage against customers: Examining emotion and resource perspectives. Academy of Management Journal, 54(2), 312-334.

Wang, C. S., Sivanathan, N., Narayanan, J., Ganegoda, D. B., Bauer, M., Bodenhausen, G. V., \& Murnighan, K. (2011). Retribution and emotional regulation: The effects of time delay in angry economic interactions. Organizational Behavior and Human Decision Processes, $116,46-54$.

Wheatley, T., \& Haidt, J. (2005). Hypnotic disgust makes moral judgments more severe. Psychological Science, 16(10), 780-784.

Wiltermuth, S. S., \& Tiedens, L. Z. (2011). Anger and the appeal of evaluating others’ ideas. Organizational Behavior and Human Decision Processes, 116(1), 55-65. 
Yip, J. A., \& Côté, S. (2013). The emotionally intelligent decision-maker: Emotion understanding ability reduces the effect of incidental anxiety on risk-taking. Psychological Science, 24(1), 48-55.

Yip, J. A., \& Schweitzer, M. E. (2015). Trust promotes unethical behavior: excessive trust, opportunistic exploitation, and strategic exploitation. Current Opinion in Psychology, 6, 216-220.

Yip, J. A., \& Schweinsberg, M. (2016). Infuriating impasses: Expressing anger increases exiting behavior in negotiations. Working paper.

Zhao, X., J.G. Lynch Jr., Q. Chen (2010). Reconsidering Baron and Kenny: Myths and truths about mediation analysis. Journal of Consumer Research, 37(August), 197-206.

Zhong, C. (2011). The ethical dangers of deliberative decision making. Administrative Science Quarterly, 56, 1-25. 
Table 1. Descriptive Statistics and Planned Comparisons of Emotion Manipulation Check $(n=179)$.

Self-Reported Emotion

\begin{tabular}{lcccccc} 
& \multicolumn{2}{c}{ Anger } & \multicolumn{2}{c}{ Neutral } & \multicolumn{2}{c}{ Sadness } \\
\cline { 2 - 7 } Emotion Condition & $M$ & $S D$ & $M$ & $S D$ & $M$ & $S D$ \\
\hline Anger (n=61) & $\mathbf{4 . 9 7}$ & 1.79 & 2.45 & 1.47 & 3.28 & 1.66 \\
Neutral (n=59) & 1.90 & 1.17 & $\mathbf{4 . 0 2}$ & 1.42 & 2.30 & 1.39 \\
Sadness (n=59) & 1.21 & .53 & 2.92 & 1.35 & $\mathbf{3 . 7 5}$ & 1.82 \\
\hline
\end{tabular}

Note. Participants reported their emotion on a scale from 1 (does not describe my feelings at all) to 7 (describes my feelings very well). Planned comparisons within each emotion condition reveal that ratings of the induced emotion are significantly different from the ratings of other emotions. 


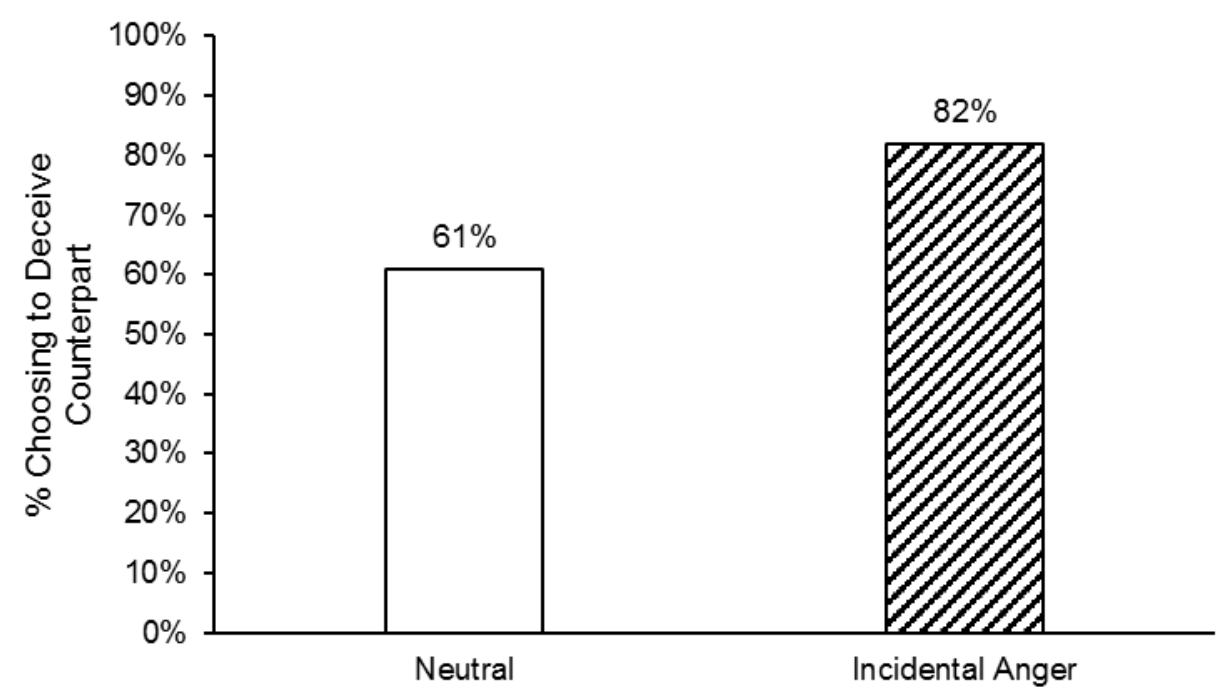

Figure 1. Study 1 demonstrates that participants in the incidental anger condition were more likely to deceive their counterparts than were participants in the neutral condition. 


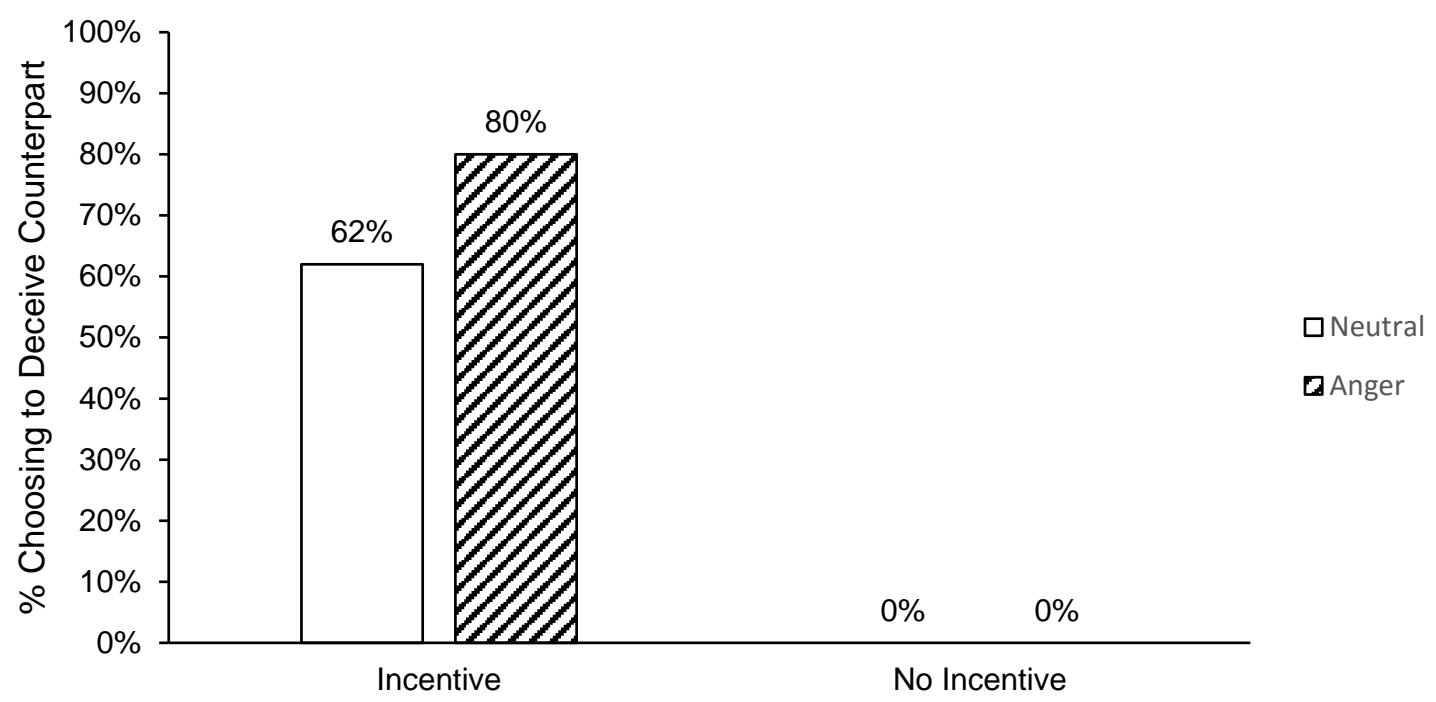

Figure 2. Study 4 shows that when a financial incentive is present, incidental anger promotes deception. When no financial incentive is present, we find no effect of incidental anger on deception. 


\section{Appendix A: Instructions for Writing \& Evaluating Essays for Study 1}

\section{General Instructions for Writing Essay}

The purpose of this study is to examine students' ability to recall and write about inspirational moments in their lives.

For this task, write a short essay about an inspirational moment in your life. This moment can come from any personal experience at any point in your life. For example, relevant topics include educational accomplishments (such as performing well on an exam or a graduation), professional accomplishments (such as a promotion or recognition for your work), or any other type of accomplishment (such as finishing a running race, summiting a mountain). You should not write about topics related to the death of a family member or a medical condition. You will have five minutes to write this essay. Please include as much detail as you can and write as clearly as you can within the five-minute time limit. Make sure that your writing is legible for others to read.

Once five minutes have passed, the experimenter will collect the essays and then redistribute them to other participants for evaluation. You will also receive an essay that was written by a different participant to evaluate.

Do NOT detach your essay form from the feedback form. Your identity will be kept confidential. Your participant ID ensures your confidentiality.

\section{General Instructions for Evaluating Essay}

In this task, you will evaluate the essay that was written by another participant in this session. You will have five minutes to provide your feedback.

1. How inspirational was the essay that you were assigned to evaluate? (Please circle a number below) 1 = Not at all; 7 = Extremely

2. What is your overall evaluation of the essay? (Please circle an option below)

\section{Pass OR Fail}

3. Please include as much detail as you can and write as clearly as you can within the fiveminute time limit. Make sure that your handwriting is legible and can be read by others. 


\section{Special Instructions for Participants to Evaluate Essays}

You will now evaluate an essay written by another participant in this session. The participant wrote an essay about an inspirational moment in his or her life.

You will have 5 minutes to read the essay and write your evaluation. Please write legibly so that the author can read your comments. Your identity will be kept confidential. The comments are important.

\section{Special Instructions for Evaluators to Evaluate Essays and Elicit Neutral Emotion}

You will now evaluate an essay written by another participant in this session. The participant wrote an essay about an inspirational moment in his or her life.

Your goal is to provide feedback that causes the other participant to feel as neutral as possible. For the first two items, you should give a high score on inspiration and indicate a "PASS" for the overall evaluation. For the comments, start with a summary of the essay. Your comments should be specific and neutral.

The comments are important. Feel free to modify the words you use. Here are some guidelines:

(1) Start with a summary

e.g., "This essay is about . It is inspirational because .

(2) Be specific

e.g., "This essay describes the following events

(3) Be neutral

e.g., "The quality of this essay meets my expectations, because

You will have 5 minutes to read the essay and write your evaluation. Please write legibly so that the author can read your comments. Your identity will be kept confidential.

\section{Special Instructions for Participants to Evaluate Essays and Elicit Anger}

You will now evaluate an essay written by another participant in this session. The participant wrote an essay about an inspirational moment in his or her life.

Your goal is to provide feedback that causes the other participant to feel as angry as possible. For the first two items, you should give a low score on inspiration and indicate a "FAIL" for the overall evaluation. For the comments, start with a critical summary of the essay. Your comments should be specific and critical.

The comments are important. Feel free to modify the words you use. Here are some guidelines: 
(1) Start with a critical summary

e.g., "This essay is about . I found to be completely uninspiring.”

(2) Be specific and critical

e.g., "This essay describes the following events , which I found to be boring/ordinary/stupid.”

e.g., "The essay was poorly written. It included phrases that a high school student would have written such as ."

(3) Be critical about the author

e.g., "The author is probably _ _ because ___."

e.g., "I am glad that I do not have to meet this person or hear more about his/her boring life."

You will have 5 minutes to read the essay and write your evaluation. Please write legibly so that the author can read your comments. Your identity will be kept confidential. 


\section{Appendix B: Feedback for Study 2 Pilot Study}

\section{[Incidental Anger Condition]}

You were matched with Participant 3154.

The essay evaluation from the participant with whom you were matched is presented below. These are his or her responses to each of the items about the essay that you wrote.

1. How inspirational is the essay that you were assigned to evaluate? ( $1=$ Not at all; 7=Extremely)

1 - NOT AT ALL

2. What is your overall evaluation of the essay? (PASS or FAIL)

FAIL

3. Please provide some comments about the essay that you read:

I am not sure whether the author did not care or did not have enough time, but I thought this essay was boring. I don't think the author understood this task. Also, I would expect that the essay would be better written given the amount of time that we were given.

\section{[Neutral Condition]}

You were matched with Participant 3154.

The essay evaluation from the participant with whom you were matched is presented below. These are his or her responses to each of the items about the essay that you wrote.

1. How inspirational is the essay that you were assigned to evaluate? ( $1=$ Not at all; 7=Extremely)

5

2. What is your overall evaluation of the essay? (PASS or FAIL) PASS

3. Please provide some comments about the essay that you read:

The author wrote an essay that was quite inspiring. He/she seemed to have thought carefully about what to write and wrote a story that is relatable. Also, the essay was well written given the amount of time that we were given. 


\section{Appendix C: Empathy Measure for Study 2}

Please answer the following questions based on how you felt after writing about the situation that you described in your essay. 1 = "Does not describe me at all”; 7 = "Describes me very well"

1. Other people’s misfortunes did not disturb me at all. (reverse-coded)

2. If I saw someone being treated unfairly, I would not feel very much pity for them. (reversecoded)

3. I did not care how events affect other people. (reverse-coded)

4. I felt concerned for people less fortunate than me.

5. I would have described myself as warm-hearted. 


\section{Appendix D: Confederate Script for Studies 2 \& 4}

In the beverage taste task, the confederate sent the following messages to participants:

MESSAGE 1:

hi! i have to choose a beverage for a taste task - which one tastes good?

MESSAGE 1A: (only use this if the participant does not specify beverage a, b, c or d) so should i choose beverage a, b, c or d?

\section{MESSAGE 2:}

do you have any information about what the beverage tastes like?

\section{MESSAGE 3:}

okay...i will take your advice.

MESSAGE 4:

thanks...bye! 